\title{
Insights into unmet need in Kenya
}

Kazuyo Machiyama

John C. Cleland

Follow this and additional works at: https://knowledgecommons.popcouncil.org/departments_sbsr-rh

Part of the Demography, Population, and Ecology Commons, Family, Life Course, and Society Commons, Gender and Sexuality Commons, International Public Health Commons, Maternal and Child Health Commons, and the Women's Health Commons How does access to this work benefit you? Let us know!

\section{Recommended Citation}

Machiyama, Kazuyo and John C. Cleland. 2013. "Insights into unmet need in Kenya," STEP UP Research Report. London: London School of Hygiene \& Tropical Medicine. 


\section{STEP ब}

STRENGTHENING EVIDENCE FOR PROGRAMMING ON UNINTENDED
KENYA

RESEARCH REPORT

FEBRUARY 2013

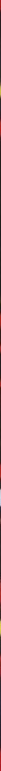

\section{Insights into Unmet Need in Kenya}

KAZUYO MACHIYAMA AND JOHN CLELAND 


\section{Insights into Unmet Need in Kenya}

KAZUYO MACHIYAMA AND JOHN CLELAND

London School of Hygiene \& Tropical Medicine

STEP UP RESEARCH REPORT

FEBRUARY 2013 
The STEP UP (Strengthening Evidence for Programming on Unintended Pregnancy) Research Programme Consortium generates policy-relevant research to promote an evidence-based approach for improving access to family planning and safe abortion. STEP UP focuses its activities in five countries: Bangladesh, Ghana, India, Kenya, and Senegal. STEP UP is coordinated by the Population Council in partnership with the African Population and Health Research Center; icddr,b; the London School of Hygiene and Tropical Medicine; Marie Stopes International; and Partners in Population and Development. STEP UP is funded by UK aid from the UK Government. www.stepup.popcouncil.org

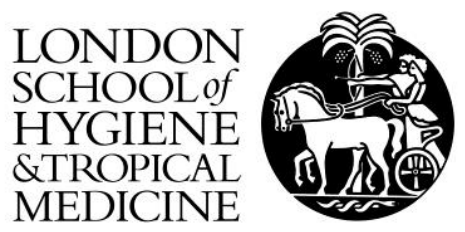

The London School of Hygiene \& Tropical Medicine is a world-leading centre for research and postgraduate education in public and global health. Our mission is to improve health and health equity in the UK and worldwide; working in partnership to achieve excellence in public and global health research, education and translation of knowledge into policy and practice. www.Ishtm.ac.uk

\section{(2) Population Council}

The Population Council confronts critical health and development issues-from stopping the spread of HIV to improving reproductive health and ensuring that young people lead full and productive lives. Through biomedical, social science, and public health research in 50 countries, we work with our partners to deliver solutions that lead to more effective policies, programs, and technologies that improve lives around the world. Established in 1952 and headquartered in New York, the Council is a nongovernmental, nonprofit organization governed by an international board of trustees. www.popcouncil.org

Suggested citation: Machiyama, K. and Cleland, J. 2013. "Insights into Unmet Need in Kenya, "STEP UP Research Report. London: London School of Hygiene \& Tropical Medicine.

(C) 2013 London School of Hygiene \& Tropical Medicine

Please address any inquiries about STEP UP to the RPC co-directors:

Dr. Harriet Birungi, hbirungi@popcouncil.org

Dr. lan Askew, iaskew@popcouncil.org

Funded by

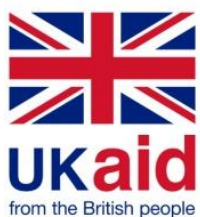




\section{Contents}

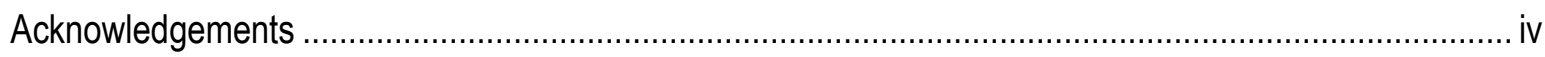

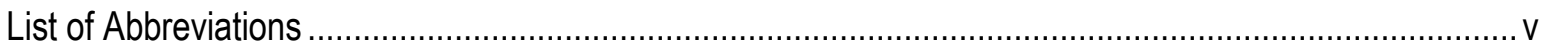

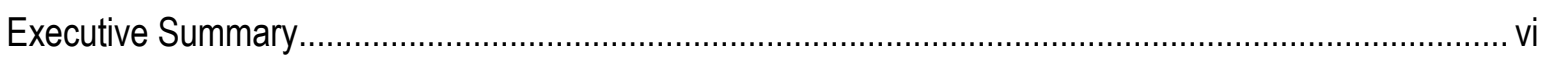

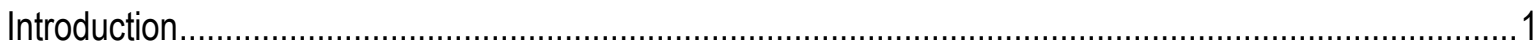

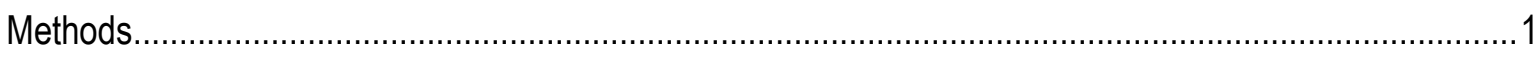

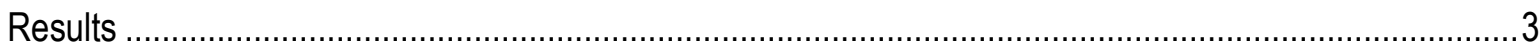

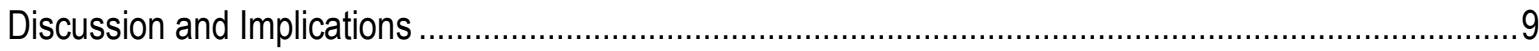

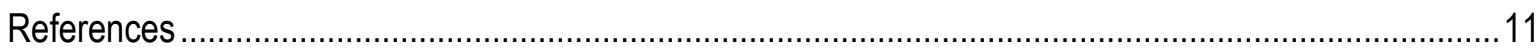

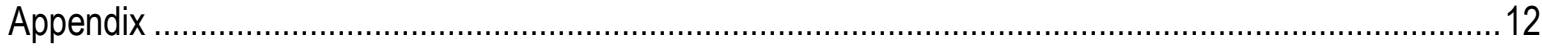




\section{Acknowledgements}

We acknowledge support from the STEP UP (Strengthening Evidence for Programming on Unintended Pregnancy) Research Programme Consortium. STEP UP is funded by UKaid from the Department for International Development. We thank lan Askew, Population Council, for his insightful comments and for coordinating this study project, and Caroline Kabiru, African Population Health Research Center, for her valuable comments. 


\section{List of Abbreviations}

FP Family planning

KDHS Kenya Demographic and Health Survey

IUD Intrauterine device

RRR Relative Risk Ratio 


\section{Executive Summary}

\section{Background}

Despite the recent increase in contraceptive prevalence, a quarter of women of reproductive age in Kenya reported unmet need for family planning in 2008/9. Any advances in our understanding of the causes of unmet need could have profound implications for programmes.

\section{Objectives}

This study aims to establish the relative importance of lack of access and attitudinal resistance towards use of contraception in different population and geographical strata of Kenya. It is intended to inform policy makers on the priority that should be given to behaviour change communication or improved access/information, and also helpful to interventions to reduce health concerns and fear of side effects, such as provision of broader method mix and better counselling.

\section{Methods}

Data from the Kenya DHS 2008/9 were used for the analysis. All analyses were based on married/cohabiting fecund women who were exposed to risk of pregnancy at the time of the survey We identified whether married women with unmet need have access (defined by knowledge of pills and injectables, and a supply source) and attitudinal acceptance (defined by intention to use in the future). We assessed variations of unmet need across different strata by bivariate and multivariate analyses. Selfreported reasons for unmet need were assessed.

\section{Results}

Among 2676 exposed women, $28 \%$ had unmet need. Of these, half were classified as possessing both access and a positive attitude and a further one-third as having access but no intention to use in the future. The majority in both groups had previously used a modern method, in most cases pills or injectables. The main self-reported reason for non-use in both groups was health concerns and fear of side effects. Small minorities (6-7\%) of women with an unfavourable attitude reported that they were opposed to contraception or mentioned religious reasons for non-use. Lack of access was associated with unmet need in $16 \%$ of cases and lack of information was the most common reason for non-use among these women. With the exception of the North Eastern Province where access was very limited, regional variations were minor. However, lack of access (i.e. method and/or supply source), was much more common in women with no schooling and the poorest segment than among other strata. Lack of access also appeared to be one reason why postpartum women have higher unmet need than other women.

\section{Discussion and implications}

Most women having unmet need for family planning in Kenya were aware of the two main contraceptive methods and a supply source, but many of the poorest, least educated women and those living in North Eastern Province were disadvantaged in this regard. Targeted expansion of access/information is a priority to meet the need of the disadvantaged populations.

Among those with access, most (68\%) have previously tried a modern method. Thus the origin of unmet need stems largely from discontinuation of use than outright rejection of contraception based on personal or religious opposition. The central problem appears to be health concerns and side effects. Many women try a modern method but discontinue use because of these concerns and do not switch to an alternative. 
The likelihood of re-adoption is difficult to gauge but $63 \%$ of past users with access stated a positive intention to use in the future.

Discontinuation of hormonal methods because of some form of dissatisfaction with the method is common in all countries and the proportion of women in Kenya who stop within 12 months is not exceptional. However, switching quickly to an alternative is known to be low in Kenya. One way to address unmet need would be to facilitate and encourage switching among the substantial minority of women who are dissatisfied with their initially chosen method. Widening the range of methods that are routinely and widely available should also help to enhance switching. Nearly three-quarters of married modern method users rely on injectables or pills. This unbalanced method-mix is typical of many countries in the region but is nevertheless unsatisfactory because of limited alternatives to hormonal methods. 


\section{Introduction}

The majority of unintended pregnancies stem from unmet need for contraception and the prime objective of family planning programmes is to reduce unmet need. According to the Kenya DHS 2008/9, a quarter of women of reproductive age still reported unmet need for family planning. Little has changed in the level of unmet need since 1998. Any advances in our understanding of the causes of unmet need could have profound implications for programmes.

The main aim of this project is to establish the relative importance of lack of access and attitudinal resistance towards use of family planning in accounting for unmet need among different population strata in Kenya. The results may be useful for policy makers in deciding the priority that should be given to behaviour change communication or improved access/information for different socio-economic strata and different geographic regions, and also helpful to interventions to reduce health concerns and fear of side effects, such as provision of broader method mix and better counselling. This report presents the results of the analysis using the latest DHS data.

\section{Methods}

Data

Data from the Kenya DHS 2008/9 were used for the analysis. Women who either want no more children or don't want a child in the next two years but are not using any method of contraception are regarded as having an unmet need for contraception. A standard definition of unmet need was used, following the most recent 2012 DHS report on unmet need (Bradley et al. 2012). However, women who were pregnant, or still abstaining or amenorrheic after the most recent birth were excluded because they were not exposed to the risk of conception at the time of the survey. Single women were also excluded because their profile of method-use is very different from that of married women and thus access cannot be measured in the same way for both groups. Specifically condoms are the main method for single women (18\%) but rarely used by married couples (1.8\%) (Kenya National Bureau of Statistics and ICF Macro 2010).

\section{Unmet need for family planning}

The main analysis is to deconstruct unmet need for family planning and to establish the relative importance of lack of access and attitudinal resistance towards use of family planning. Ansley Coale (1973) suggested that fast sustained fertility transition needs a large fraction of population who are 'ready, willing and able' to use contraceptives. Following the modification by Lesthaeghe and Vanderhoeft (2001), Cleland et al.(2011) developed novel measures in order to assess the extent to which populations possess these three preconditions for use and to measure trends. We extended and adapted the approach used in an investigation of progress in family planning need, access and attitude in Africa (Cleland et al. 2011). That study developed a novel measure of physical access: knowledge of the two most popular modern methods in sub-Saharan Africa, pills and injectables, and knowledge of a supply source. This measure is not ideal for two main reasons. First, knowledge of methods may include misinformation. Second, the restriction to pills and injectables is obviously a partial measure of knowledge of contraceptive methods 
but is justified by the fact that they account for three-quarters of all modern method use and, among nonusers who intend to use in the future, only a minority of $18 \%$ mention long-acting alternatives, such as sterilisation, IUDs or implants, as their preferred method, according to KDHS 2008/9. Awareness of a source is also not ideal because it tells us nothing about travelling time or distance. Nevertheless, awareness of the two dominant methods and where to obtain them captures the two most fundamental components of access.

The 2011 study also used answers to questions on approval of family planning as the measure of attitude but these questions were omitted from the most recent round of DHSs. Preliminary analysis showed that a woman's approval was strongly associated with her intention to use in the future. In the $2003 \mathrm{KDHS}, 52 \%$ of women who approved of family planning had an intention to use in the future compared with only $3.5 \%$ of those who disapproved. Clearly approval and intention are not identical, but $95 \%$ of those who intend to use approved family planning. Therefore it seems valid to interpret intention as an indicator of broader attitude for the purposes of this report.

Based on these two measures, we identified whether the women having unmet need for family planning had access to, and attitudinal acceptance of, contraception. We divided the study population into 7 groups: (a) unmet need: has access and attitude; (b) unmet need: has access, but not attitude; (c) unmet need: has attitude, but not access; and (d) unmet need: has neither access nor attitude, and (e) using modern methods for spacing; (f) using modern methods for limiting; and (g) desire to have another child within 2 years. Categories $e$ and $f$ represent met need while category $g$ denotes no need. The detailed definitions can be found in Table A.1 in Appendix.

The question on knowledge of source of family planning was asked only of women who were not using any type of family planning, including traditional methods. Since traditional method users were not asked whether they knew a family planning source, they were excluded from the analysis. These women accounted for about $8.8 \%$ of the married/cohabiting fecund women who were exposed to risk of pregnancy in the 2008/9 Kenya DHS data.

\section{Population strata}

To identify groups of women with the different types of unmet need, we assessed associations between various geographical and socio-economic population strata (residence, region, respondent's education and age, household wealth, a combined measure of wealth and urban-rural residence, a combined measure of education and residence) and reproductive status (parity, recency of last birth, breastfeeding status, past use of a modern method).

\section{Analysis}

We first assessed association between unmet need for family planning and various population/ geographical strata using $x^{2}$ tests. Then multivariate logistic regression and multinomial logistic regression analyses were employed to estimate adjusted probabilities of having unmet need in various population strata. In addition, reasons for non-use of family planning were explored. 


\section{Results}

The analysis is based on 2,676 exposed married women and who were not using a traditional method (See Table A.2).

Figure 1 presents proportions of women having unmet need for family planning, using a modern method and desiring a child within the next two years. More than a quarter (28\%) of women had unmet need for family planning, while $59 \%$ were using modern contraceptives either for spacing or limiting. Among those having unmet need for family planning, a half reported access and a positive attitude. A large minority $(42 \%)$ lacked a positive attitude but only $16 \%$ had no access.

Figure 1: Unmet need, modern method use and fertility desire, Kenya DHS 2008/9

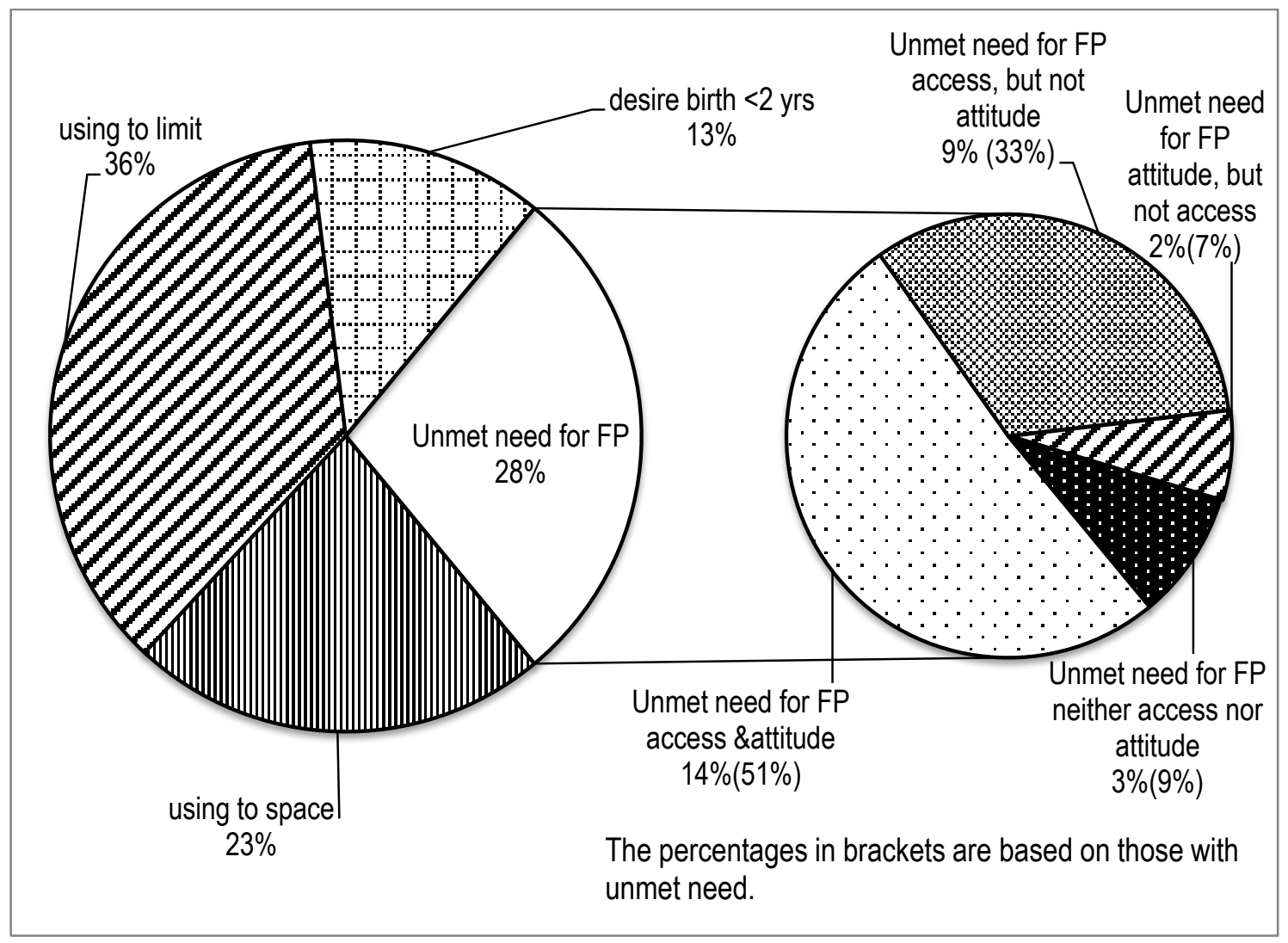

Inequalities in unmet need across various population and geographical strata were substantial. Table A.3 presents distributions of unmet need, fertility preference, and modern method use by the strata ${ }^{1}$. In particular, differences across provinces, wealth quintiles, women's education, and by postpartum and breastfeeding status, were large.

1 Traditional and folkloric methods (including lactational amenorrhea) users were not regarded as modern method users. 
There were large regional variations. In Coast, Nyanza, Rift Valley and North Eastern Provinces over 33\% of the women had unmet need. But access and attitudinal acceptance varied among the four provinces. While $62 \%$ of women with unmet need in Nyanza had access and attitude, over $36 \%$ of women in Coast and Rift Valley Provinces had access but did not intend to use family planning in the future. Interpretation of the results in North Eastern region needs to be cautious due to the small sample size but, in this province, about $90 \%$ either wanted a child within two years or reported neither access nor attitude.

Figure 2: Unmet need for family planning by province

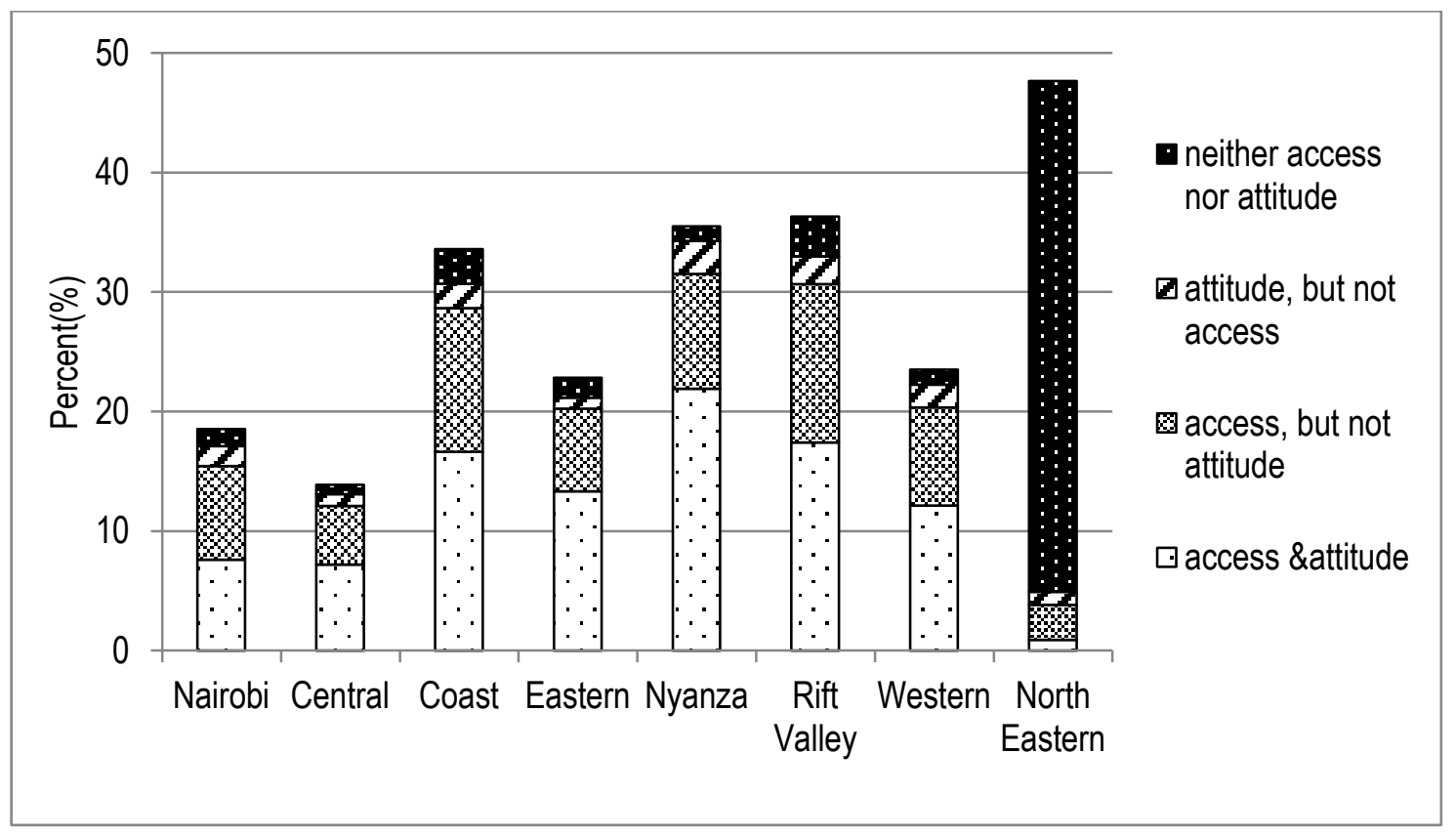

Figure 3 shows unmet need across different wealth quintiles. One-half of women in the poorest quintile had unmet need compared with only $22 \%$ in the richest quintile. Women who had neither access nor attitude were disproportionally concentrated in the poorest quintile but differences in proportions having access but no intention were modest.

Educational inequality was also large. Only $17 \%$ of women with secondary education compared with $43 \%$ of women with no education had unmet need (see Figure 4). Furthermore, a half of women with no education and unmet need for family planning were classified as having neither access nor attitude. However, the percentages of women with access but without positive attitude did not vary greatly across the three educational groups. 
Figure3: Unmet need for family planning by wealth quintile

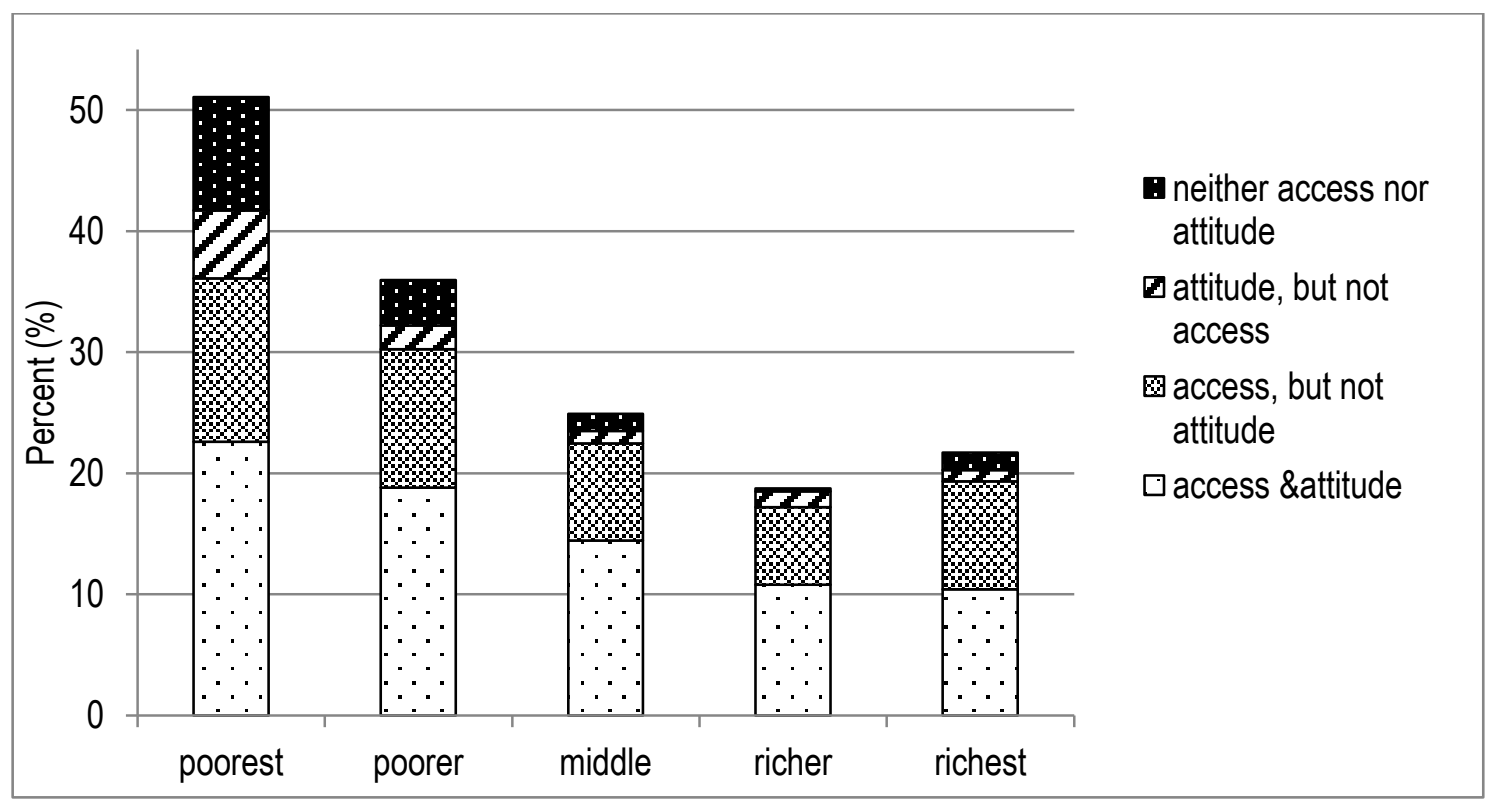

Figure4: Unmet need for family planning by level of mother's education

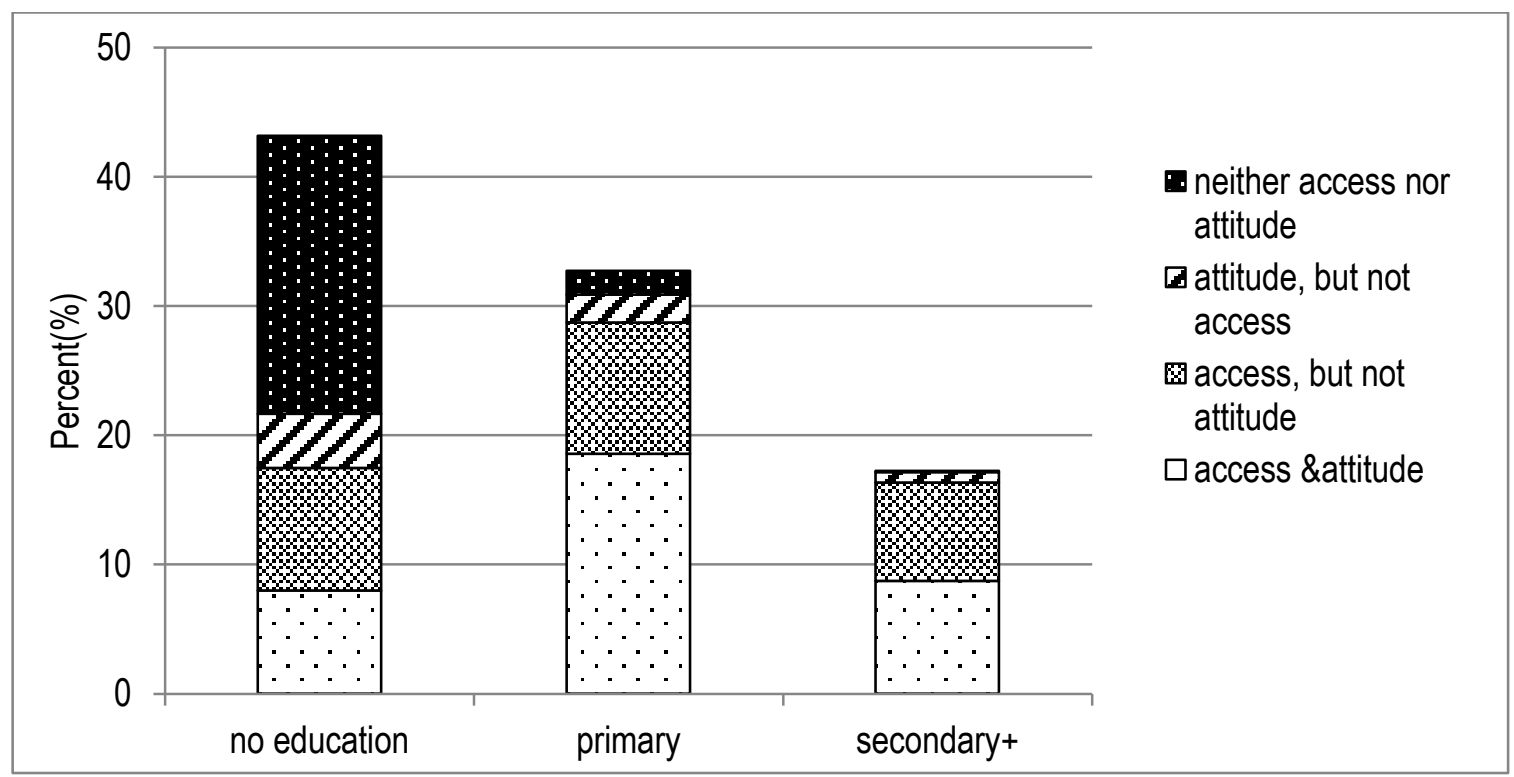

One of the groups with the highest unmet need was women who had a birth within the past 2 years. Among these women, 37\% reported unmet need compared with 25\% among women who had a birth 2 years or more ago (see Figure 5). Over half of the postpartum women with unmet need had no apparent problems of access or attitude. As presented in Table A.3 on page 22, breastfeeding women with a recent birth differed little from women who had weaned their child in the level of unmet need but the latter were more likely to want another child within two years. However, among women whose most recent birth was 2 years or more ago, the minority still breastfeeding had higher unmet need than others. 
Figure 5: Unmet need for family planning by postpartum status

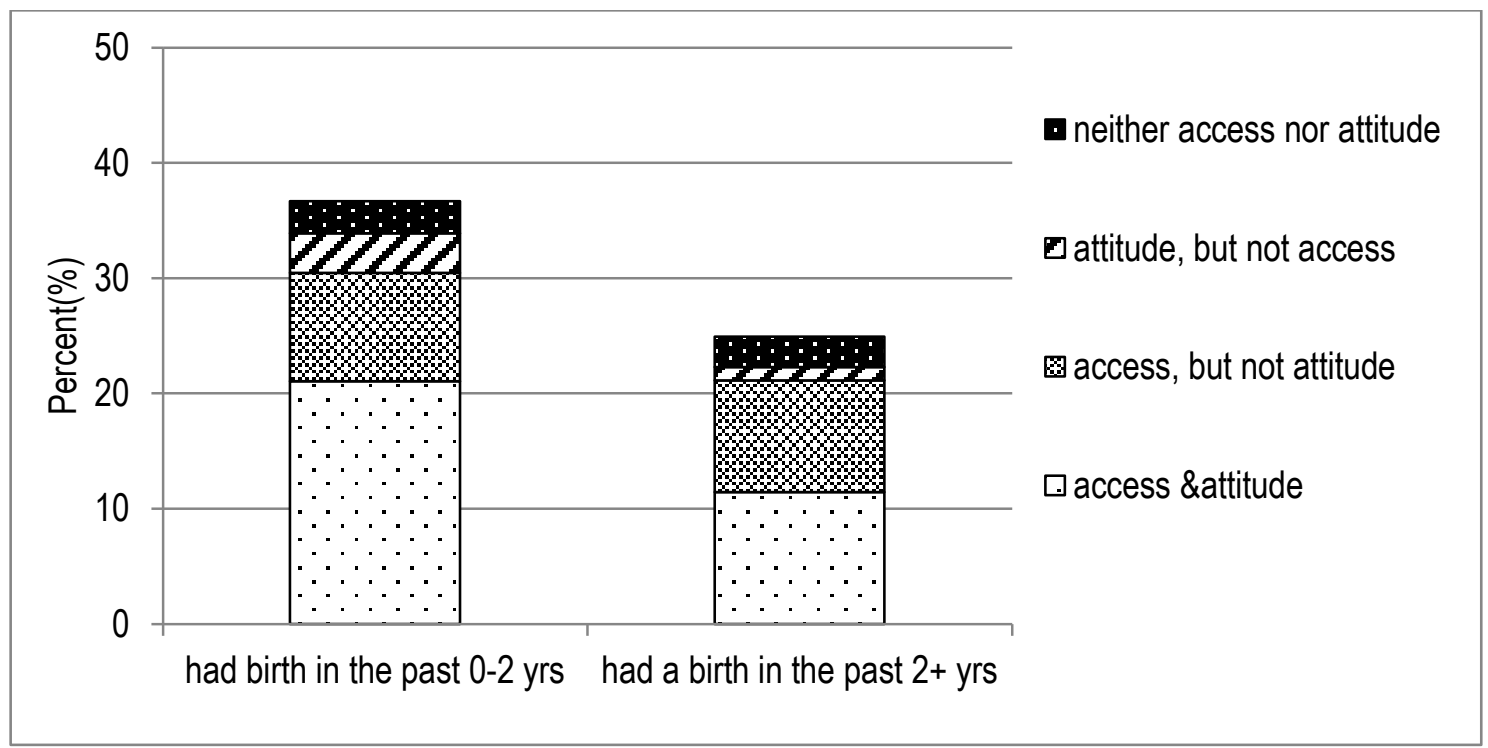

As shown in Figure 6, 66\% of the women who have never used a modern method had unmet need and about half had no intention of using in the future. Among the majority group who had prior experience of modern contraception, only $20 \%$ had unmet need and one third of these had an unfavourable attitude. Of all 749 women with unmet need, $60 \%$ had earlier tried a modern method and, among these, a large majority $(88 \%)$ had used pills or injectables.

Among all exposed women defined as having a need for contraception, $61 \%$ wanted no more children and $39 \%$ wanted to postpone childbearing for at least two years. Levels of modern method use and unmet need in the two groups were almost identical, suggesting that spacing and limitation are equally important motives for contraceptive use in Kenya (Table A.3).

Figure 6: Unmet need for family planning by ever use of modern method

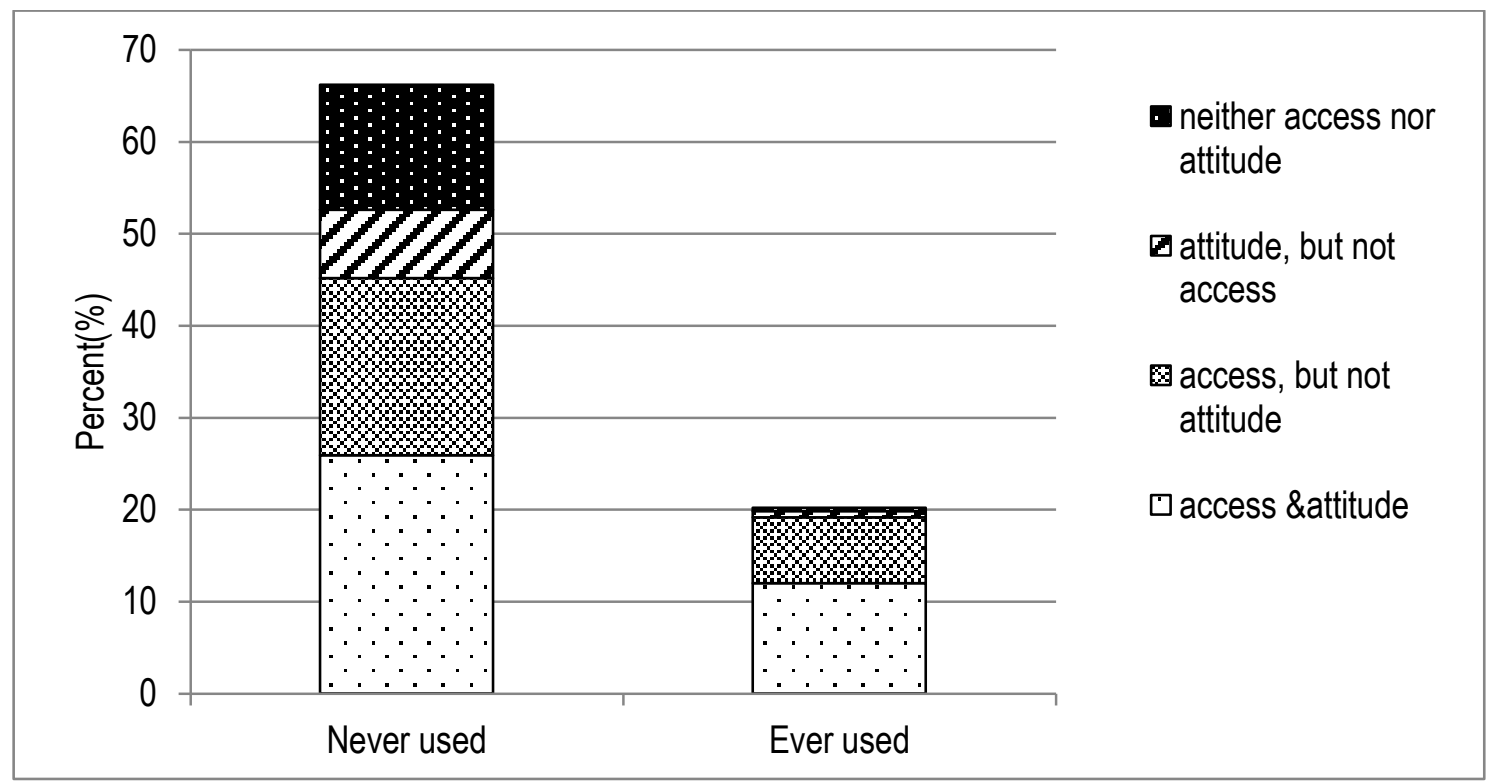




\section{Multivariate and multinomial logistic regression}

The analysis so far has been descriptive. In order to more closely identify the factors that give rise to unmet need, logistic regression was applied and results are shown in Table A.4. The adjusted odds ratios indicate the association between background factors and having unmet need versus being a modern method user, after controlling for other factors.

Rather few significant effects at the $95 \%$ confidence level are found. Compared with the middle wealth quintile, the poorest segment of the population is nearly three times more likely to have unmet need, after controlling for education and other factors in the model. The next poorest segment also records higher unmet need. Education is a significant predictor of unmet need. Compared with women of primary schooling, those with secondary or higher education are less likely to have an unmet need. Unmet need is not statistically related to urban-rural residence, women's age or parity. Postpartum women have 1.43 times higher unmet need than others. As very few women in Central and Nairobi had no schooling or fell into the poorest quintile, Eastern Province was selected as a reference. Relative to Eastern Province, unmet need is slightly but not significantly lower in Nairobi/Central Provinces and Western Province, but higher in Coast, Nyanza, Rift Valley and North Eastern Provinces.

The results of a more complex multivariate analysis, using multinomial logistic regression are shown in Table A.5. Non-users were here divided into four categories based on our four combinations of access and attitude, together with a fifth category of those who want a child in the next two years and thus have no unmet need but a convincing reason for non-use. The adjusted relative risk ratios show the ratio of probability of being in each of these five categories of non-use relative to probability of being a modern method user. For instance, the top row shows that rural women were 1.14 times more likely than urban women to be a non-user with access and a positive attitude than to be a current user but less likely to be a non-user with access but a negative attitude. However, these results were not statistically significant.

The most pronounced effects in Table A.5 concern wealth and education. Compared with those of middle wealth, the poorest women were significantly more likely to belong to each of the four categories of unmet and more likely to want another child soon. Lack of access is a particular challenge for the poorest women. Compared to women with a primary school level of education, those who never attended school were also much more likely to lack access and to combine lack of access with negative attitude towards use. They were also significantly more likely to want a child soon.

Postpartum women, relative to those who had a birth more than 2 years ago record a high adjusted risk ratios of having unmet need without apparent problem in access and attitude, or intend to use but do not have access. Women with small families compared with those with three to four children were more likely to have a positive attitude but no access than to be a current user. Unsurprisingly, the probability of wanting a child soon is lower for postpartum women but higher for those with less than three children.

Relative to those in Eastern Province, women in Nyanza, Western and North Eastern Provinces were more likely to desire a child soon than to be a current user. The results indicate that negative attitudes are of a barrier in Coast (relative risk ratio, RRR: $2.09,95 \% \mathrm{Cl}$ [0.98-4.48] and Rift Valley (RRR: 2.11 95\% Cl [1.14-3.91] than elsewhere, but the results were of borderline statistical significance. The adjusted RRR of having neither access nor attitude are vastly higher in North Eastern Province than in other parts of Kenya. 


\section{Reasons for non-use of family planning}

In answer to a question on reasons for unmet need, multiple responses were permitted and about $10 \%$ gave more than one reason (Table A.6). The main reasons for non-use were health concerns or side effects (see Table 1). As shown in Figure 4, women who had ever used modern contraception were significantly more likely to cite health concerns $(\mathrm{p}=0.0125)$ and infrequent sex as reasons than never users $(p<0.001)$. Health concern was also the main reported reason among never users, but they were more likely to offer opposition and lack of knowledge as reasons than past users.

Table 1 allows a comparison of the four categories of unmet need, defined in terms of access and attitude, with self-reported reasons. A reasonable consistency was apparent. Among women defined as having access and a positive attitude, health concerns/side effects is mentioned by over half as a reason for nonuse. Other reasons commonly given were infrequent sex, breastfeeding and the opposition of the partner or others. The profile of reasons given by the group with access but no intention to use in the future was similar. Health concerns were again dominant but respondent's opposition and religion were more likely to be mentioned. Among the much smaller groups with a positive attitude but no access and those with neither access nor attitude, health concern was the most common reason, followed by lack of knowledge. In both these small groups, opposition by partner or others is also a common reason but respondent's own opposition is much more commonly cited by women with neither access nor attitude than by those without access but who intend to use. In general there is reasonable consistency between self-reported reasons and the independent measures of access and attitude.

Table 1: Reasons for non-use of family planning

\begin{tabular}{|c|c|c|c|c|c|}
\hline \multirow[b]{2}{*}{ Reasons for not using family planning } & \multicolumn{4}{|c|}{ unmet need for family planning } & \multirow[b]{2}{*}{ Total } \\
\hline & $\begin{array}{l}\text { access } \\
\text { \&attitude }\end{array}$ & $\begin{array}{l}\text { access, } \\
\text { but not } \\
\text { attitude }\end{array}$ & $\begin{array}{l}\text { attitude, } \\
\text { but not } \\
\text { access }\end{array}$ & $\begin{array}{l}\text { neither } \\
\text { access } \\
\text { nor } \\
\text { attitude }\end{array}$ & \\
\hline Respondent's opposition & 1.1 & 6.9 & 1.4 & 17.6 & 4.2 \\
\hline Partner's/others' opposition & 8.6 & 6.6 & 12.8 & 16.9 & 8.7 \\
\hline Religion & 1.0 & 6.2 & 4.1 & 11.5 & 3.7 \\
\hline Lack of knowledge & 1.3 & 0.0 & 24.9 & 23.8 & 3.9 \\
\hline Access/cost & 6.2 & 4.2 & 5.7 & 8.5 & 5.6 \\
\hline $\begin{array}{l}\text { Health concerns/side effect/interfere with } \\
\text { body }\end{array}$ & 52.5 & 57.9 & 34.8 & 22.1 & 51.3 \\
\hline Infrequent or no sex & 13.0 & 15.4 & 1.8 & 7.6 & 12.8 \\
\hline Breastfeeding & 8.7 & 1.6 & 2.9 & 6.5 & 5.7 \\
\hline Others/don't know & 12.5 & 11.2 & 11.9 & 6.1 & 11.6 \\
\hline$N$ & 348 & 231 & 45 & 42 & 666 \\
\hline
\end{tabular}

Note: 83 women did not provide any answer to the questions on reasons for not-use of family planning. Women provided multiple answers.

Variations in self-reported reasons across population strata were examined but few significant differences were found (data not shown). Educated women were less likely than the less educated to cite personal objection to contraception but more likely to mention side effects. Women in North Eastern Province were 
much more likely to give personal objection as a reason than women in other provinces. Reasons given by women who wanted no more children were almost identical to those given by women who wanted to space or postpone.

Figure 7: Reasons for non-use of family planning

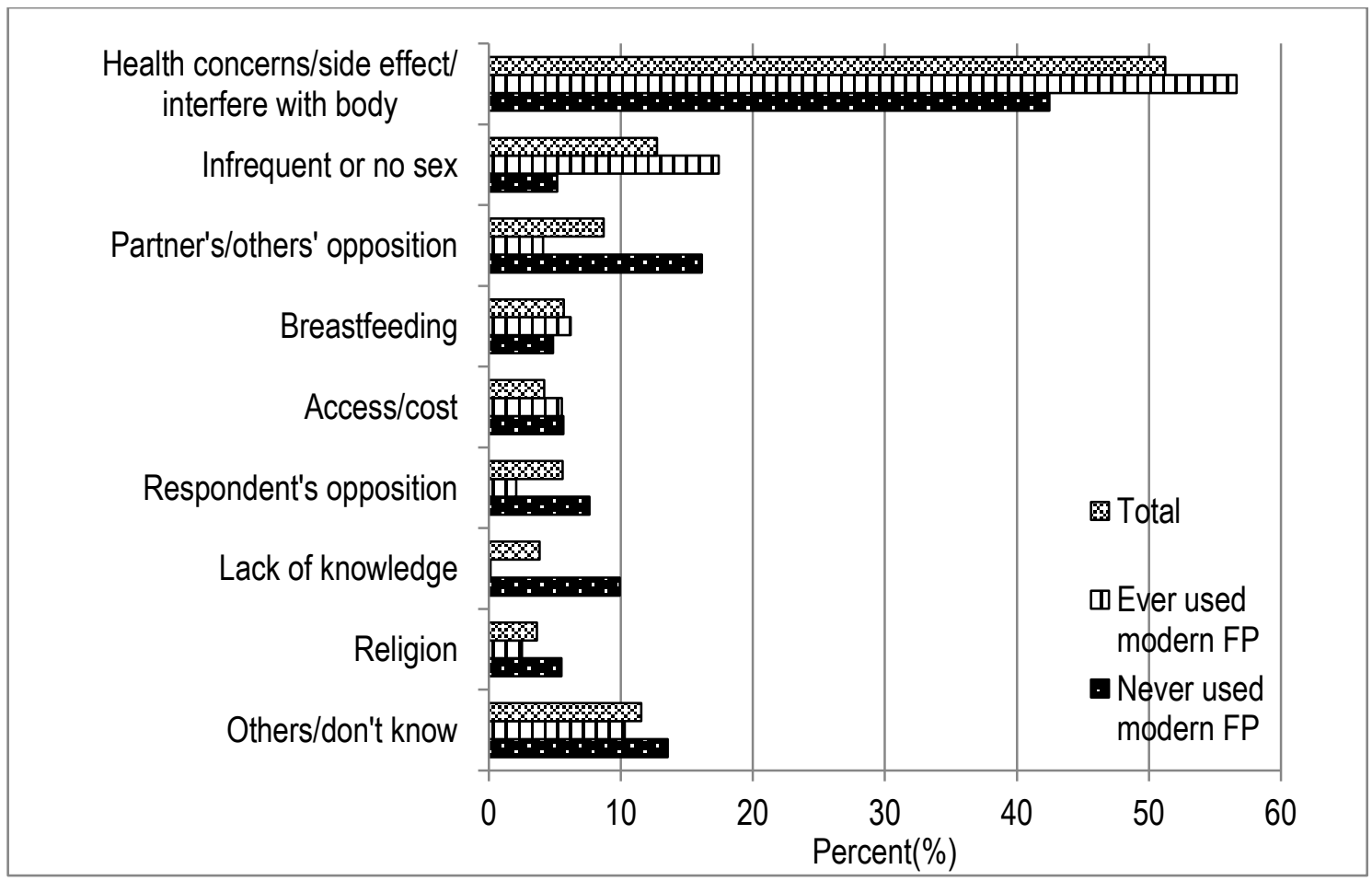

\section{Discussion and Implications}

Unmet need for contraception remains high in Kenya. Among married women exposed to the risk of pregnancy at the time of the survey, $28 \%$ were using no method, a revised estimate of unmet need similar to that given in the DHS Analytical Report (Bradley et al. 2012). Half of this $28 \%$ reported knowledge of pills and injectables (the most commonly used methods by married women), knew of a supply source and they reported an intention to use in the future. Thus neither access nor attitude appears to provide a ready explanation for non-use. The majority (61\%) had used a modern method in the past, predominantly pills or injectables. The main reason for non-use appears to be health concerns and side effects, an answer given by over half to a direct question on reasons for non-use.

The next largest category of unmet need, accounting for about one-third of all unmet need, comprised women who had access but did not intend to use in the future. Again the dominant reason for non-use was health concerns and side effects. Two-thirds had previously used a modern method. These similarities between the two categories suggest that a strong a distinction between them should not be drawn. Deeprooted rejection of contraception does not appear to be common. Only minorities of women classified as having an unfavorable attitude cited their own opposition or religion as a reason for non-use.

These results are nevertheless of concern because they suggest that many women in Kenya have tried pills or injectables in the past but health concerns and fear of side effects persist despite (or because of) 
this experience. It is well established from other research that discontinuation of both pills and injectables is high and that the main reason for stopping use is the same as for non-use, namely worries about health and side effects. An analysis using the 2003 Kenya DHS found that the probabilities of stopping pills and injectables within 12 months of starting because of dissatisfaction with the method were 30 and 23, respectively per 100 episodes (Ali, Cleland and Shah 2012). These results were similar to those in other countries. However, the proportion of discontinuing women who promptly switch to another method was much lower in Kenya, at 35\%, than in most other countries. It may be concluded that much unmet in Kenya arises as follows. Women try a hormonal method, are disturbed by side effects, stop use but are neither motivated nor perhaps sufficiently encouraged by providers to try an alternative method. The programmatic implication is clear cut. Providers should be aware that many women will not be willing to persist with their initially chosen method and should inform clients that alternatives exist should the need arise. The evidence also supports the desirability of widening the range of methods that are routinely available. Nearly three quarters of married modern method users rely on injectables and pills. While awareness of long-acting alternatives such as sterilization, implants and IUDs is reasonably high, at over $60 \%$ (Kenya National Bureau of Statistics and ICF Macro 2010), it is likely that ready access to them is limited. Another important justification for greater emphasis on long-acting methods stems from the fact that $61 \%$ of women with unmet need wanted no more children.

For a minority, about $15 \%$, of women with unmet need, lack of access or information was still a barrier to adoption. This figure did not vary much by province, except for the small number of respondents in the North Eastern Province, where a majority were unaware of methods and a supply source. This underpopulated outlying region has been marginalized in development terms. Caution is also needed for the results from the North Eastern Province due to the small sample size. Lack of access is also higher in Nyanza than elsewhere. However, it does largely account for the high overall level of unmet need among women who never attended school and, to a lesser extent, among the poorest.

Unmet need was found to be higher among women who had a child in the two years prior to the survey. Breastfeeding in Kenya lasts on average for 21 months (Kenya National Bureau of Statistics and ICF Macro 2010) and most women who had given birth in the past two years had not yet weaned the child. Fear of using a modern method while breastfeeding may be part of the explanation but, surprisingly, the multivariate analysis showed that lack of access was significantly higher among postpartum women than others. In Kenya, about $23 \%$ of second and higher order births occur within 24 months of the birth of an elder sibling (Kenya National Bureau of Statistics and ICF Macro 2010) which puts them at higher risk of death and impaired growth. This figure underscores the importance of a focused effort to improve postpartum contraception.

Kenya has one of the longest records of successful family planning programmes in Africa. But this report has revealed some major defects, in particular excess reliance on two hormonal methods. Most important single result is that over half of the women with unmet need have tried one of these two methods, and hesitate to re-use them. Major future progress may well depend on successful popularisation of other methods, particularly long-acting and permanent methods. Broadening the method mix will require simultaneous effort to stimulate the demand and increase access. 


\section{References}

Ali, M.M., J.G. Cleland, and I.H. Shah. 2012. Causes and consequences of contraceptive discontinuation: evidence from 60 Demographic and Health Surveys. Geneva, Switzerland: WHO.

Bradley, S.E.K., T.N. Croft, J.D. Fishel, and C.F. Westoff. 2012. Revising unmet need for family planning. DHS Analytical Studies. No.25. Calverton, MD: ICF Macro. Retrieved from http:www.measuredhs.com/pubs/pdf/AS25/AS25[12June2012].pdf.

Cleland, J.G., R.P. Ndugwa, and E.M. Zulu. 2011. Family planning in sub-Saharan Africa: progress or stagnation? Bulletin of the World Health Organization 89(2):137-143.

Coale, A.J. 1973. The demographic transition reconsidered. (Eds). International Union for the Scientific Study of Population, Liege, Belgium.

Kenya National Bureau of Statisticsand ICF Macro. 2010. Kenya Demographic and Health Survey 200809. Calverton, Maryland: KNBS and ICF Macro. Retrieved from http://www.measuredhs.com/pubs/pdf/FR229/FR229.pdf.

Lesthaeghe, R.and C. Vanderhoeft. 2001. Ready, willing, and able: a conceptualization of transitions to new behavioral forms. Pp. 240-264. in J.B. Casterline (Eds). Diffusion processes and fertility transition: selected perspectives, Washington, D.C.: National Academy Press. 


\section{Appendix}

Table A.1: Definition of indicators used for the analysis (All indicators are confined to fecund/non-pregnant, non-abstaining currently married or co-habiting women)

\begin{tabular}{l|l|l}
\hline & \multicolumn{1}{|c|}{ Indicator } & \multicolumn{1}{c}{ Definition } \\
\hline 1 & $\begin{array}{l}\text { Unmet need for FP (access \& } \\
\text { attitude) }\end{array}$ & $\begin{array}{l}\text { \% of all women who have access (knowledge of pills and } \\
\text { injectables, and a supply source) and attitude (intention to use } \\
\text { in the future) to FP use and want to delay next child for at least } \\
\text { 2+ year, but NOT using modern method among all women }\end{array}$ \\
\hline 2 & $\begin{array}{l}\text { Unmet need for FP (access \& but not } \\
\text { attitude) }\end{array}$ & $\begin{array}{l}\text { \% of all women who have access, but do have attitude to FP } \\
\text { use and want to delay next child for at least 2+ year, but NOT } \\
\text { using modern method among all women }\end{array}$ \\
\hline 3 & $\begin{array}{l}\text { Unmet need for FP (attitude, but not } \\
\text { access) }\end{array}$ & $\begin{array}{l}\text { \% of all women who have attitude, but do not have access to } \\
\text { FP use and want to delay next child for at least 2+ year, but } \\
\text { NOT using modern method among all women }\end{array}$ \\
\hline 4 & $\begin{array}{l}\text { Unmet need for FP (neither access } \\
\text { nor attitude) }\end{array}$ & $\begin{array}{l}\text { \% of all women who have neither access nor attitude to FP } \\
\text { use and want to delay next child for at least 2+ year, but NOT } \\
\text { using modern method among all women }\end{array}$ \\
\hline 5 & $\begin{array}{l}\text { Want another child and using any } \\
\text { modern method }\end{array}$ & $\begin{array}{l}\text { \% of all women who want to delay next child for at least 2+ } \\
\text { year and using modern method among all women }\end{array}$ \\
\hline 6 & $\begin{array}{l}\text { Want no more children and using any } \\
\text { modern method for limiting }\end{array}$ & $\begin{array}{l}\text { \% of all women who want no more child and using modern } \\
\text { method among all women }\end{array}$ \\
\hline 7 & $\begin{array}{l}\text { Desire a birth within 2 years } \\
\text { all all women who want another child within 2 years among } \\
\text { all women (excluding modern contraceptive current) }\end{array}$ \\
\hline
\end{tabular}

Table A.2: Distributions of women, Kenya DHS 2008/9

\begin{tabular}{|c|c|c|c|}
\hline & & Weighted N & $\%$ \\
\hline \multirow{6}{*}{ 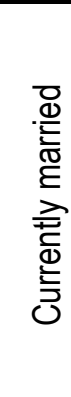 } & Exposed to pregnancy risk at survey & 2,676 & 31.7 \\
\hline & $\begin{array}{l}\text { Fecund \& not postpartum abstaining, but data on knowledge of } \\
\text { a supply source or intention for future FP use were not collected } \\
\text { or missing }^{\text {a }}\end{array}$ & 250 & 3.0 \\
\hline & Fecund \& postpartum abstaining & 64 & 0.8 \\
\hline & Pregnant & 525 & 6.2 \\
\hline & Postpartum amenorrhea & 786 & 9.3 \\
\hline & Infecund, menopausal & 627 & 7.4 \\
\hline \multicolumn{2}{|c|}{ Never/formerly married } & 3,516 & 41.6 \\
\hline \multicolumn{2}{|c|}{ Total } & 8,444 & 100.0 \\
\hline
\end{tabular}


Table A.3: Distribution of unmet need for family planning and modern method use and fertility desire

\begin{tabular}{|c|c|c|c|c|c|c|c|c|c|c|c|c|c|}
\hline & & \multicolumn{2}{|c|}{ Total } & \multicolumn{2}{|c|}{ Residence } & \multicolumn{8}{|c|}{ Province } \\
\hline & & $\begin{array}{l}\text { Weighted } \\
\qquad \mathrm{N}\end{array}$ & $\%$ & urban & rural & Nairobi & Central & Coast & Eastern & Nyanza & $\begin{array}{c}\text { Rift } \\
\text { Valley }\end{array}$ & Western & $\begin{array}{c}\text { North } \\
\text { Eastern }\end{array}$ \\
\hline \multicolumn{14}{|c|}{ Percentages } \\
\hline \multirow{4}{*}{ 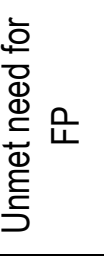 } & access \&attitude & 383 & 14.3 & 9.9 & 15.9 & 7.6 & 7.2 & 16.6 & 13.3 & 21.9 & 17.4 & 12.2 & 0.9 \\
\hline & access, but not attitude & 247 & 9.2 & 9.2 & 9.2 & 7.9 & 4.9 & 12.0 & 6.9 & 9.6 & 13.3 & 8.2 & 2.9 \\
\hline & attitude, but not access & 49 & 1.8 & 1.0 & 2.1 & 1.7 & 1.0 & 2.1 & 0.9 & 2.8 & 2.3 & 1.9 & 1.1 \\
\hline & $\begin{array}{l}\text { neither access nor } \\
\text { attitude }\end{array}$ & 70 & 2.6 & 1.4 & 3.0 & 1.4 & 0.8 & 2.9 & 1.7 & 1.2 & 3.3 & 1.2 & 42.7 \\
\hline \multirow{3}{*}{\multicolumn{2}{|c|}{$\begin{array}{l}\text { using to space } \\
\text { using to limit } \\
\text { desire birth <2 yrs }\end{array}$}} & 613 & 22.9 & 35.6 & 18.4 & 34.4 & 25.8 & 27.7 & 17.9 & 19.1 & 22.8 & 23.1 & 5.9 \\
\hline & & 968 & 36.2 & 28.7 & 38.8 & 31.1 & 50.6 & 20.1 & 49.2 & 29.1 & 31.6 & 40.3 & 1.4 \\
\hline & & 346 & 12.9 & 14.3 & 12.5 & 16.1 & 9.7 & 18.7 & 10.1 & 16.4 & 9.4 & 13.1 & 45.1 \\
\hline \multicolumn{2}{|l|}{ Total } & 2676 & 100.0 & 100.0 & 100.0 & 100.0 & 100.0 & 100.0 & 100.0 & 100.0 & 100.0 & 100.0 & 100.0 \\
\hline \multicolumn{2}{|c|}{ Total unmet need } & 749 & 28.0 & 21.5 & 30.3 & 18.5 & 13.9 & 33.6 & 22.8 & 35.5 & 36.3 & 23.5 & 47.6 \\
\hline \multicolumn{2}{|c|}{$p$-value for chi-square test } & & & & $<0.001$ & & & & & & & & $<0.001$ \\
\hline
\end{tabular}

\begin{tabular}{|c|c|c|c|c|c|c|c|c|c|c|c|c|}
\hline \multicolumn{13}{|c|}{ Weighted N } \\
\hline \multirow{4}{*}{ 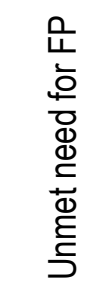 } & access \&attitude & 383 & 70 & 314 & 18 & 26 & 35 & 60 & 94 & 117 & 34 & 0 \\
\hline & access, but not attitude & 247 & 65 & 182 & 18 & 18 & 25 & 31 & 41 & 90 & 23 & 1 \\
\hline & attitude, but not access & 49 & 7 & 42 & 4 & 4 & 4 & 4 & 12 & 16 & 5 & 1 \\
\hline & $\begin{array}{l}\text { neither access nor } \\
\text { attitude }\end{array}$ & 70 & 10 & 60 & 3 & 3 & 6 & 7 & 5 & 23 & 3 & 19 \\
\hline \multicolumn{2}{|c|}{ using to space } & 613 & 250 & 363 & 81 & 93 & 58 & 81 & 82 & 154 & 64 & 3 \\
\hline \multirow{2}{*}{\multicolumn{2}{|c|}{$\begin{array}{l}\text { using to limit } \\
\text { desire birth }<2 \text { yrs }\end{array}$}} & 968 & 202 & 766 & 73 & 182 & 42 & 221 & 125 & 213 & 112 & 1 \\
\hline & & 346 & 101 & 246 & 38 & 35 & 39 & 45 & 70 & 63 & 37 & 20 \\
\hline \multicolumn{2}{|l|}{ Total } & 2676 & 704 & 1972 & 234 & 359 & 208 & 450 & 428 & 675 & 278 & 45 \\
\hline
\end{tabular}




\begin{tabular}{|c|c|c|c|c|c|c|c|c|c|c|c|}
\hline & & \multicolumn{2}{|c|}{ Mother's age } & \multicolumn{3}{|c|}{ Mother's education } & \multicolumn{5}{|c|}{ Wealth } \\
\hline \multicolumn{12}{|c|}{ Percentages } \\
\hline \multirow{2}{*}{ 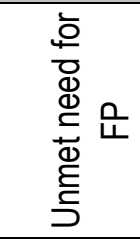 } & access \&attitude & 17.4 & 11.8 & 8.0 & 18.6 & 8.7 & 22.6 & 18.8 & 14.5 & 10.8 & 10.4 \\
\hline & neither access nor attitude & 2.4 & 2.8 & 21.5 & 1.9 & 0.1 & 9.4 & 3.7 & 1.4 & 0.2 & 1.4 \\
\hline \multicolumn{2}{|c|}{ using to space } & 36.7 & 11.7 & 6.1 & 20.6 & 30.0 & 10.4 & 16.2 & 19.1 & 25.1 & 33.9 \\
\hline \multicolumn{2}{|c|}{ using to limit } & 16.4 & 52.3 & 19.2 & 35.9 & 40.0 & 20.0 & 35.1 & 45.6 & 45.2 & 30.7 \\
\hline \multicolumn{2}{|c|}{ desire birth <2 yrs } & 18.5 & 8.4 & 31.5 & 10.8 & 12.8 & 18.6 & 12.8 & 10.4 & 11.0 & 13.7 \\
\hline \multicolumn{2}{|l|}{ Total } & 100.0 & 100.0 & 100.0 & 100.0 & 100.0 & 100.0 & 100.0 & 100.0 & 100.0 & 100.0 \\
\hline
\end{tabular}

\begin{tabular}{|c|c|c|c|c|c|c|c|c|c|c|c|}
\hline \multicolumn{12}{|c|}{ Weighted N } \\
\hline \multirow{3}{*}{ 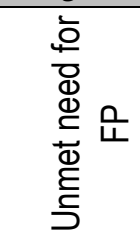 } & access \&attitude & 209 & 174 & 15 & 286 & 82 & 81 & 84 & 77 & 64 & 79 \\
\hline & access, but not attitude & 77 & 169 & 18 & 157 & 72 & 48 & 51 & 43 & 38 & 67 \\
\hline & attitude, but not access & 28 & 21 & 8 & 33 & 8 & 20 & 9 & 5 & 8 & 7 \\
\hline \multicolumn{2}{|c|}{ using to space } & 441 & 172 & 11 & 318 & 284 & 37 & 72 & 102 & 147 & 255 \\
\hline \multicolumn{2}{|c|}{ using to limit } & 197 & 771 & 36 & 553 & 379 & 71 & 156 & 243 & 266 & 232 \\
\hline
\end{tabular}




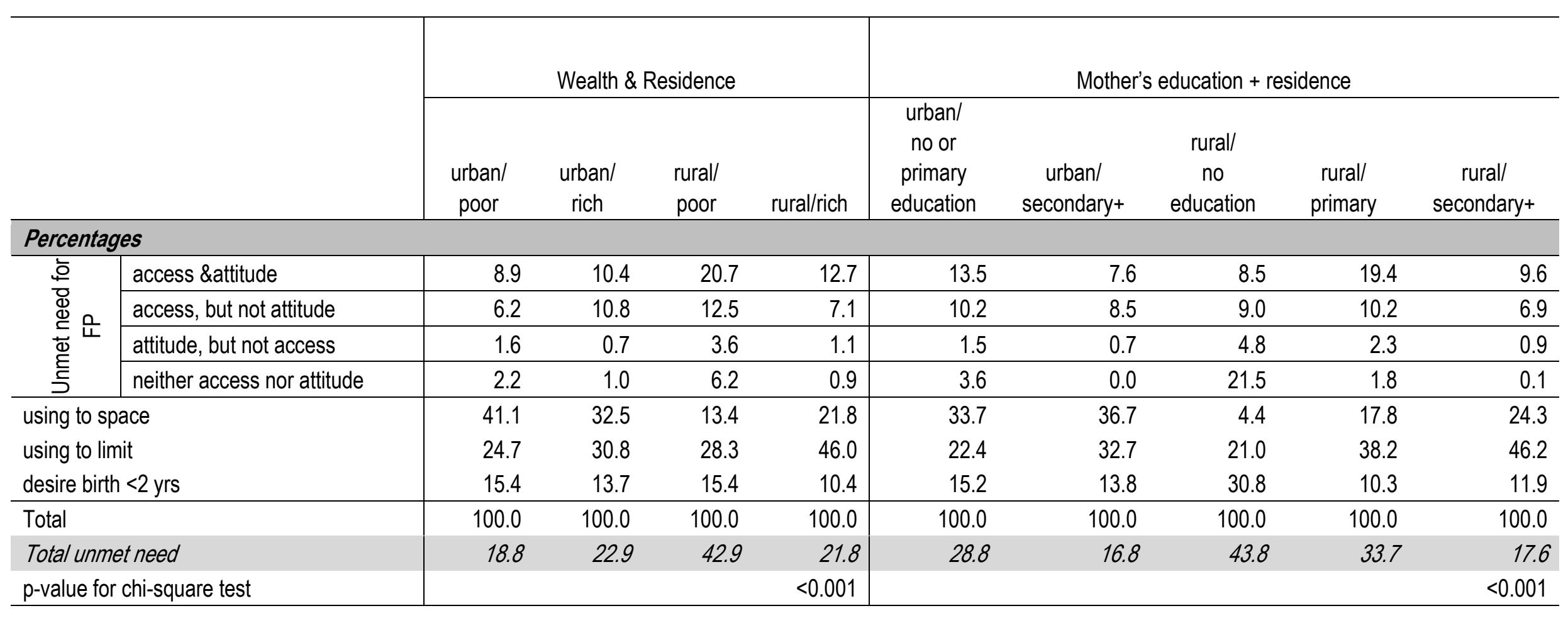

\begin{tabular}{|c|c|c|c|c|c|c|c|c|c|c|}
\hline \multicolumn{11}{|c|}{ Weighted N } \\
\hline \multirow{4}{*}{ 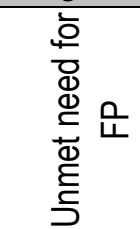 } & access \&attitude & 22 & 48 & 164 & 150 & 37 & 33 & 14 & 250 & 50 \\
\hline & access, but not attitude & 15 & 49 & 99 & 83 & 28 & 37 & 15 & 132 & 36 \\
\hline & attitude, but not access & 4 & 3 & 29 & 13 & 4 & 3 & 8 & 29 & 5 \\
\hline & neither access nor attitude & 5 & 4 & 49 & 11 & 10 & 0 & 35 & 24 & 1 \\
\hline \multicolumn{2}{|c|}{ using to space } & 102 & 149 & 106 & 257 & 92 & 158 & 7 & 231 & 125 \\
\hline \multicolumn{2}{|c|}{ using to limit } & 61 & 141 & 225 & 541 & 61 & 141 & 35 & 493 & 238 \\
\hline
\end{tabular}




\begin{tabular}{|c|c|c|c|c|c|c|c|c|}
\hline & \multicolumn{3}{|c|}{ Postpartum } & \multicolumn{2}{|c|}{ Postpartum(last birth <2 yrs) } & \multicolumn{2}{|c|}{ Non-postpartum (last birth $>=2 \mathrm{yrs}$ ) } \\
\hline & & no children & $\begin{array}{l}\text { had birth } \\
\text { in the } \\
\text { past 0-2 } \\
\text { yrs }\end{array}$ & $\begin{array}{c}\text { had a } \\
\text { birth in } \\
\text { the past } \\
2+\text { yrs }\end{array}$ & $\begin{array}{l}\text { Not currently } \\
\text { breastfeeding }\end{array}$ & $\begin{array}{c}\text { Currently } \\
\text { breastfeeding }\end{array}$ & $\begin{array}{l}\text { Not currently } \\
\text { breastfeeding }\end{array}$ & $\begin{array}{c}\text { Currently } \\
\text { breastfeeding }\end{array}$ \\
\hline \multicolumn{9}{|c|}{ Percentages } \\
\hline \multirow{4}{*}{ 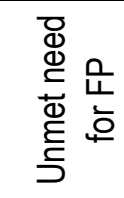 } & access \&attitude & 12.4 & 21.1 & 11.5 & 20.4 & 21.3 & 10.8 & 19.0 \\
\hline & access, but not attitude & 0.3 & 9.4 & 9.7 & 10.0 & 9.2 & 9.6 & 11.3 \\
\hline & attitude, but not access & 1.1 & 3.4 & 1.2 & 1.2 & 4.2 & 1.1 & 2.4 \\
\hline & neither access nor attitude & 1.0 & 2.8 & 2.6 & 1.9 & 3.1 & 2.2 & 8.1 \\
\hline \multirow{3}{*}{\multicolumn{2}{|c|}{$\begin{array}{l}\text { using to space } \\
\text { using to limit } \\
\text { desire birth }<2 \text { yrs }\end{array}$}} & 19.2 & 29.2 & 20.4 & 24.6 & 30.7 & 20.3 & 21.4 \\
\hline & & 0.7 & 25.5 & 43.2 & 22.9 & 26.4 & 44.3 & 29.2 \\
\hline & & 65.4 & 8.6 & 11.5 & 19.0 & 5.2 & 11.7 & 8.6 \\
\hline \multicolumn{2}{|l|}{ Total } & 100.0 & 100.0 & 100.0 & 100.0 & 100.0 & 100.0 & 100.0 \\
\hline \multicolumn{2}{|c|}{ Total unmet need } & 14.8 & 36.7 & 24.9 & 33.5 & 37.7 & 23.6 & 40.8 \\
\hline \multicolumn{2}{|c|}{$p$-value for chi-square test } & & & $<0.001$ & & 0.009 & & 0.007 \\
\hline
\end{tabular}

\begin{tabular}{|c|c|c|c|c|c|c|c|c|}
\hline \multicolumn{9}{|c|}{ Weighted N } \\
\hline \multirow{4}{*}{ 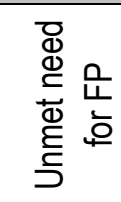 } & access \&attitude & 14 & 167 & 203 & 40 & 126 & 177 & 26 \\
\hline & access, but not attitude & 0 & 75 & 172 & 20 & 55 & 156 & 15 \\
\hline & attitude, but not access & 1 & 27 & 21 & 2 & 25 & 17 & 3 \\
\hline & neither access nor attitude & 1 & 22 & 47 & 4 & 18 & 36 & 11 \\
\hline \multicolumn{2}{|c|}{ using to space } & 22 & 231 & 361 & 49 & 182 & 332 & 29 \\
\hline \multirow{2}{*}{\multicolumn{2}{|c|}{$\begin{array}{l}\text { using to limit } \\
\text { desire birth <2 yrs }\end{array}$}} & 1 & 202 & 765 & 46 & 156 & 725 & 39 \\
\hline & & 74 & 68 & 204 & 38 & 31 & 192 & 12 \\
\hline \multicolumn{2}{|l|}{ Total } & 113 & 791 & 1772 & 199 & 592 & 1636 & 135 \\
\hline
\end{tabular}




\begin{tabular}{|c|c|c|c|c|c|c|c|c|}
\hline & & \multicolumn{3}{|c|}{ Parity } & \multicolumn{2}{|c|}{ Motivation } & \multicolumn{2}{|c|}{ Use of modern FP } \\
\hline & & $0-2$ children & $\begin{array}{c}3 \text { or } 4 \\
\text { children }\end{array}$ & $5+$ children & Spacer & Limiter & Never used & Ever used \\
\hline \multicolumn{9}{|l|}{ Percentages } \\
\hline \multirow{4}{*}{ 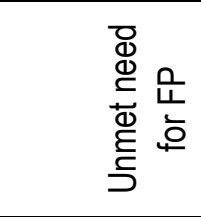 } & access \&attitude & 12.3 & 14.1 & 17.5 & 18.2 & 15.3 & 25.9 & 12.0 \\
\hline & access, but not attitude & 5.6 & 9.4 & 14.1 & 7.2 & 12.8 & 19.2 & 7.2 \\
\hline & attitude, but not access & 2.0 & 1.1 & 2.4 & 2.3 & 2.0 & 7.4 & 0.7 \\
\hline & neither access nor attitude & 1.0 & 2.9 & 4.6 & 5.4 & 1.4 & 13.6 & 0.4 \\
\hline \multirow{3}{*}{\multicolumn{2}{|c|}{$\begin{array}{l}\text { using to space } \\
\text { using to limit } \\
\text { desire birth }<2 \text { yrs }\end{array}$}} & 41.4 & 16.0 & 4.6 & 66.9 & 0.0 & 0.0 & 27.6 \\
\hline & & 15.4 & 47.5 & 52.8 & 0.0 & 68.5 & 0.0 & 43.5 \\
\hline & & 22.4 & 8.9 & 4.0 & 0.0 & 0.0 & 33.8 & 8.7 \\
\hline \multicolumn{2}{|l|}{ Total } & 100.0 & 100.0 & 100.0 & 100.0 & 100.0 & 100.0 & 100.0 \\
\hline \multicolumn{2}{|c|}{ Total unmet need } & 20.8 & 27.6 & 38.6 & 33.1 & 31.5 & 66.2 & 20.2 \\
\hline \multicolumn{2}{|c|}{$p$-value for chi-square test } & & & $<0.001$ & & $<0.001$ & & $<0.001$ \\
\hline \multicolumn{9}{|l|}{ Weighted N } \\
\hline \multirow{4}{*}{ 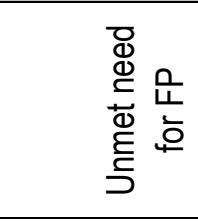 } & access \&attitude & 131 & 120 & 132 & 167 & 217 & 117 & 266 \\
\hline & access, but not attitude & 60 & 80 & 107 & 66 & 181 & 87 & 160 \\
\hline & attitude, but not access & 21 & 10 & 18 & 21 & 28 & 34 & 15 \\
\hline & neither access nor attitude & 10 & 25 & 35 & 50 & 20 & 62 & 8 \\
\hline \multicolumn{2}{|l|}{ using to space } & 442 & 136 & 35 & 613 & 0 & 0 & 613 \\
\hline \multicolumn{2}{|l|}{ using to limit } & 165 & 403 & 400 & 0 & 968 & 0 & 968 \\
\hline \multicolumn{2}{|c|}{ desire birth < 2 yrs } & 240 & 76 & 31 & 0 & 0 & 153 & 194 \\
\hline \multicolumn{2}{|l|}{ Total } & 1069 & 849 & 758 & 917 & 1413 & 452 & 2224 \\
\hline
\end{tabular}


Table A.4: Adjusted odds ratios for unmet versus using a modern method

\begin{tabular}{|c|c|c|c|c|}
\hline \multirow{2}{*}{ Residence (ref. urban) } & Adjusted OR & \multicolumn{3}{|c|}{$95 \% \mathrm{Cl}$} \\
\hline & & & & \\
\hline Rural & 0.89 & 0.62 & 1.27 & \\
\hline Region (ref. Eastern) & & & & \\
\hline Nairobi/Central & 0.80 & 0.51 & 1.26 & \\
\hline Coast & 1.71 & 1.04 & 2.81 & * \\
\hline Nyanza & 1.88 & 1.23 & 2.89 & ** \\
\hline Rift Valley & 1.69 & 1.11 & 2.56 & * \\
\hline Western & 0.80 & 0.51 & 1.24 & \\
\hline North Eastern & 7.51 & 2.43 & 23.20 & *** \\
\hline Wealth (ref. Middle) & & & & \\
\hline Poorest & 2.97 & 1.90 & 4.64 & $* * *$ \\
\hline Poor & 1.54 & 1.04 & 2.29 & * \\
\hline Rich & 0.79 & 0.51 & 1.22 & \\
\hline Richest & 1.11 & 0.71 & 1.74 & \\
\hline Education (ref. primary education) & & & & \\
\hline No education & 1.45 & 0.79 & 2.66 & \\
\hline Secondary + & 0.55 & 0.38 & 0.80 & ** \\
\hline Postpartum (ref. had a birth 2+ yrs ago) & & & & \\
\hline Had a birth <2 yrs ago & 1.43 & 1.09 & 1.88 & * \\
\hline Parity (ref. 3-4 children) & & & & \\
\hline $0-2$ children & 0.90 & 0.59 & 1.35 & \\
\hline $5+$ children & 1.33 & 0.96 & 1.84 & \\
\hline Mother's age (ref.<30 yrs) & & & & \\
\hline $30+$ years old & 0.88 & 0.59 & 1.32 & \\
\hline Weighted $\mathrm{Na}^{\mathrm{a}}$ & 2330 & & & \\
\hline
\end{tabular}

a Women who desired another birth within 2 years and were not using any modern method were excluded from this analysis.

${ }^{*} p<0.05,{ }^{* *} p<0.01,{ }^{* * *} p<0.001$ 
Table A.5. Adjusted relative risk ratios of belonging to specified categories of unmet need or wanting a child soon versus being a modern method user

\begin{tabular}{|c|c|c|c|c|c|c|c|c|c|c|c|c|c|c|c|c|c|c|c|c|}
\hline & \multicolumn{16}{|c|}{ Unmet need for family planning vs modern method users } & \multirow{2}{*}{\multicolumn{4}{|c|}{ Desire birth within 2 yrs }} \\
\hline & \multicolumn{4}{|c|}{ Access \& attitude } & \multirow{2}{*}{\multicolumn{4}{|c|}{\begin{tabular}{|c|c}
\multicolumn{2}{|c}{ Access, no attitude } \\
RRR & $95 \% \mathrm{Cl}$ \\
\end{tabular}}} & \multicolumn{4}{|c|}{ Attitude, no access } & \multicolumn{4}{|c|}{ Neither access nor attitude } & & & & \\
\hline & $\mathrm{RRR}^{\mathrm{a}}$ & \multicolumn{3}{|c|}{$95 \% \mathrm{Cl}$} & & & & & RRR & \multicolumn{3}{|c|}{$95 \% \mathrm{Cl}$} & RRR & \multicolumn{3}{|c|}{$95 \% \mathrm{Cl}$} & \begin{tabular}{l|l} 
RRR & $95 \% \mathrm{Cl}$ \\
\end{tabular} & \multicolumn{3}{|c|}{$95 \% \mathrm{Cl}$} \\
\hline \multicolumn{2}{|c|}{ Residence (ref. urban) } & & & & & & & & & & & & & & & & & & & \\
\hline $\begin{array}{c}\text { Rural } \\
\text { Province (ref. Easte }\end{array}$ & rn) 1.14 & 0.66 & 1.95 & & 0.63 & 0.38 & 1.07 & & 1.02 & 0.23 & 4.52 & & 0.92 & 0.21 & 4.12 & & 1.08 & 0.62 & 1.89 & \\
\hline Nairobi/Central & 0.64 & 0.37 & 1.12 & & 0.91 & 0.47 & 1.73 & & 2.18 & 0.56 & 8.44 & & 1.00 & 0.25 & 4.00 & & 1.02 & 0.59 & 1.76 & \\
\hline Coast & 1.78 & 1.03 & 3.09 & * & 2.09 & 0.98 & 4.48 & & 1.74 & 0.47 & 6.50 & & 1.01 & 0.32 & 3.16 & & 1.60 & 0.87 & 2.95 & \\
\hline Nyanza & 1.82 & 1.08 & 3.06 & * & 1.75 & 0.93 & 3.29 & & 3.58 & 0.94 & 13.69 & & 1.04 & 0.30 & 3.67 & & 2.31 & 1.37 & 3.91 & $* *$ \\
\hline Rift Valley & 1.39 & 0.81 & 2.39 & & 2.11 & 1.14 & 3.91 & * & 2.32 & 0.59 & 9.05 & & 1.81 & 0.65 & 5.06 & & 0.93 & 0.52 & 1.66 & \\
\hline Western & 0.72 & 0.40 & 1.30 & & 0.95 & 0.45 & 2.02 & & 1.49 & 0.33 & 6.78 & & 0.71 & 0.19 & 2.69 & & 1.84 & 1.06 & 3.20 & $*$ \\
\hline $\begin{array}{c}\text { North Eastern } \\
\text { Wealth (ref. Middle) }\end{array}$ & 0.43 & 0.06 & 2.94 & & 2.17 & 0.43 & 10.98 & & 1.84 & 0.24 & 14.42 & & 29.71 & 6.18 & 142.82 & $* * *$ & 14.68 & 3.89 & 55.44 & $* * *$ \\
\hline Poorest & 2.43 & 1.44 & 4.09 & $* *$ & 2.90 & 1.49 & 5.62 & $* *$ & 8.35 & 2.63 & 26.53 & $* * *$ & 3.68 & 1.40 & 9.68 & $* *$ & 2.93 & 1.65 & 5.21 & $* * *$ \\
\hline Poor & 1.36 & 0.88 & 2.11 & & 1.64 & 0.83 & 3.27 & & 2.04 & 0.59 & 7.00 & & 2.94 & 1.01 & 8.56 & * & 1.53 & 0.82 & 2.85 & \\
\hline Rich & 0.81 & 0.46 & 1.41 & & 0.80 & 0.42 & 1.50 & & 1.32 & 0.40 & 4.40 & & 0.16 & 0.04 & 0.63 & $* *$ & 0.88 & 0.52 & 1.48 & \\
\hline Riches & 1.06 & 0.57 & 1.98 & & 1.10 & 0.57 & 2.13 & & 1.01 & 0.16 & 6.45 & & 2.31 & 0.35 & 15.14 & & 0.98 & 0.53 & 1.79 & \\
\hline \multicolumn{21}{|c|}{ Education (ref. primary education) } \\
\hline No education & 0.61 & 0.31 & 1.20 & & 1.11 & 0.49 & 2.49 & & 2.77 & 1.08 & 7.10 & * & 9.26 & 4.05 & 21.17 & $* * *$ & 6.35 & 3.42 & 11.81 & $* * *$ \\
\hline Secondary + & 0.54 & 0.32 & 0.89 & * & 0.69 & 0.43 & 1.10 & & 0.44 & 0.17 & 1.14 & & 0.04 & 0.01 & 0.22 & $* * *$ & 0.77 & 0.53 & 1.11 & \\
\hline \multicolumn{21}{|c|}{ Postpartum (ref. had a birth $2+$ yrs ago) } \\
\hline $\begin{array}{r}\text { Had a birth }<2 \text { yrs } \\
\text { ago }\end{array}$ & 1.58 & 1.12 & 2.22 & ** & 1.16 & 0.80 & 1.69 & & 2.54 & 1.22 & 5.27 & * & 0.78 & 0.39 & 1.55 & & 0.38 & 0.24 & 0.60 & 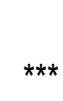 \\
\hline \multicolumn{21}{|c|}{ Parity (ref 3-4 children) } \\
\hline $0-2$ children & 0.95 & 0.64 & 1.40 & & 0.76 & 0.34 & 1.70 & & 2.67 & 1.02 & 6.96 & * & 0.61 & 0.22 & 1.70 & & 3.91 & 2.44 & 6.27 & $* * *$ \\
\hline $5+$ children & 1.35 & 0.91 & 2.01 & & 1.30 & 0.80 & 2.12 & & 1.85 & 0.72 & 4.75 & & 0.92 & 0.38 & 2.23 & & 0.29 & 0.16 & 0.52 & $* * *$ \\
\hline \multicolumn{21}{|c|}{ Mother's age (ref.<30 yrs) } \\
\hline 30 +years old & 0.63 & 0.37 & 1.07 & & 1.44 & 0.89 & 2.34 & & 0.98 & 0.44 & 2.16 & & 0.90 & 0.39 & 2.09 & & 0.92 & 0.61 & 1.40 & \\
\hline $\mathrm{N}^{b}$ & 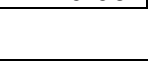 & & & 383 & & & & 247 & & & & 49 & & & & 70 & & & & 346 \\
\hline
\end{tabular}


Table A.6: Number of reasons for non-use per woman

unmet need for family planning

\begin{tabular}{|c|c|c|c|c|c|c|}
\hline No of reasons & & access \&attitude & $\begin{array}{l}\text { access, but } \\
\text { not attitude }\end{array}$ & $\begin{array}{l}\text { attitude, but } \\
\text { not access }\end{array}$ & $\begin{array}{l}\text { neither access } \\
\text { nor attitude }\end{array}$ & Total \\
\hline & 0 & 9.3 & 6.5 & 8.9 & 39.1 & 11.1 \\
\hline & 1 & 83.4 & 80.2 & 85.8 & 51.2 & 79.5 \\
\hline & 2 & 7.3 & 12.4 & 5.3 & 7.2 & 8.9 \\
\hline & 3 & 0.0 & 0.9 & 0.0 & 2.3 & 0.5 \\
\hline & 4 & 0.0 & 0.0 & 0.0 & 0.2 & 0.0 \\
\hline Total & & 100 & 100 & 100 & 100 & 100 \\
\hline
\end{tabular}




\section{www.stepup.popcouncil.org}

The STEP UP (Strengthening Evidence for Programming on Unintended Pregnancy) Research Programme Consortium generates policy-relevant research to promote an evidence-based approach for improving access to family planning and safe abortion. STEP UP focuses its activities in five countries: Bangladesh, Ghana, India, Kenya, and Senegal.

STEP UP is coordinated by the Population Council in partnership with the African Population and Health Research Center; icddr,b; the London School of Hygiene and Tropical Medicine; Marie Stopes International; and Partners in Population and Development. STEP UP is funded by UK aid from the UK Government. 